\title{
How US Air Force Space Command Optimizes Long-Term Investment in Space Systems
}

\author{
Gerald G. Brown • Robert F. Dell \\ Operations Research Department, Naval Postgraduate School, Monterey, California 93943 \\ Heath Holtz \\ Air Force Material Command Directorate of Requirements, Office of Aerospace Studies, \\ Kirtland AFB, New Mexico 87117-5776 \\ Alexandra M. Newman \\ Division of Economics and Business, Colorado School of Mines, Golden, Colorado 80401 \\ gbrown@nps.navy.mil • dell@nps.navy.mil • holtzhm@earthlink.net • newman@mines.edu
}

This paper was refereed.

\begin{abstract}
United States Air Force Space Command spends billions of dollars each year acquiring and developing launch vehicles and space systems. The space systems in orbit must continually meet defensive and offensive requirements and remain interoperable over time. Space Command can launch additional space systems only if it has a launch vehicle of sufficient capability. Space planners using space and missile optimization analysis (SAMOA) consider a 24-year time horizon when determining which space assets and launch vehicles to fund and procure. A key tool within SAMOA is an integer linear program called the space command optimizer of utility toolkit (SCOUT) that Space Command uses for long-range planning. SCOUT gives planners insight into the annual funding profiles needed to meet Space Command's acquisition goals. The 1999 portfolio of 74 systems will cost about $\$ 310$ billion and includes systems that can lift satellites into orbit; yield information on space, surface, and subsurface events, activities, and threats; and destroy terrestrial, airborne, and space targets. (Planning: government. Programming: integer.)
\end{abstract}

"Therefore doth heaven divide the state of man in divers functions setting endeavor in continual motion."

William Shakespeare, Henry $V$

$\mathrm{T}$ he Air Force created Space Command in 1982 to enhance the defense of the United States through space superiority and to protect the country from weapons of mass destruction (United States Air Force 2000). Space Command has five primary mission areas: space support, space control, force enhancement, force application, and mission support. The space support mission area launches satellites and other payloads into space and monitors them. The space control mission area monitors and counters foreign activities. The force enhancement mission area provides information on weather, navigation, intelligence, and threats, and provides communications. The force application mission area maintains and operates an intercontinental ballistic missile system. The mission support mission area provides the foundation for all other mission areas through the depart- 
ments of civil engineering, logistics, security forces, space training, education and exercise, and medicine.

Space Command spends billions of dollars a year procuring and deploying launch vehicles and space systems required for mission area tasks. By system, we mean an existing system or a concept for a future system. Every two years, Space Command updates its strategic master plan that delineates the systems to procure. The strategic master plan is the foundation for Space Command's contribution to the program objective memorandum submitted to the secretary of defense. The program objective memorandum is a compendium of funding requests from all the military services and defense agencies for the next six fiscal years. Its purpose is to justify resource requirements and programs that satisfy the secretary's defenseplanning guidance.

Planning the procurement and deployment of launch vehicles and space systems and justifying their costs is challenging. The systems are sophisticated and costly (Table 1). For example, space-based radar

\begin{tabular}{|c|c|c|c|c|}
\hline System & & FOC & Life & $\begin{array}{l}\text { Annual Cost } \\
\text { (\$ million) }\end{array}$ \\
\hline \multicolumn{5}{|l|}{ Information systems or programs } \\
\hline $\begin{array}{l}\text { National environment monitoring } \\
\text { satellite system }\end{array}$ & $\begin{array}{l}\text { Will provide global data from various altitudes with weather } \\
\text { satellites in different orbits }\end{array}$ & 12 & $16^{+}$ & 516 \\
\hline National polar orbiting system & $\begin{array}{l}\text { Will aid in acquiring information about the terrestrial and space } \\
\text { environment needed for mission planning }\end{array}$ & 10 & 24 & 152 \\
\hline $\begin{array}{l}\text { Security forces modernization } \\
\text { program }\end{array}$ & $\begin{array}{l}\text { Provides vehicles, alarm systems, encryption devices, motion } \\
\text { detectors, etc., to enhance the security of launch facilities } \\
\text { and weapon storage areas }\end{array}$ & 0 & $26^{+}$ & 7 \\
\hline Space-based radar system & Will detect terrestrial and airborne objects & 10 & $20^{+}$ & 1,022 \\
\hline \multicolumn{5}{|l|}{ Launch systems } \\
\hline Atlas and Delta launch vehicles & $\begin{array}{l}\text { Provide launches for, for example, global-positioning systems } \\
\text { and the space-based radar }\end{array}$ & 0 & 6 & 33 \\
\hline Conventional strike system & $\begin{array}{l}\text { Used as a platform to deliver precision-guided bombs at } \\
\text { high velocity to terrestrial targets }\end{array}$ & 0 & $25^{+}$ & 50 \\
\hline Evolved expendable launch vehicle & $\begin{array}{l}\text { Will provide rapid launches of, for example, global-positioning } \\
\text { systems and the space-based laser more readily and cheaply } \\
\text { than current launchers }\end{array}$ & 3 & 21 & 536 \\
\hline Space maneuver vehicle & $\begin{array}{l}\text { Will provide rapid launches of, for example, global-positioning } \\
\text { systems and the space-based laser, into various orbits }\end{array}$ & 8 & $22^{+}$ & 425 \\
\hline \multicolumn{5}{|l|}{ Defense systems } \\
\hline Helicopter replacement system & $\begin{array}{l}\text { Will provide upgrades (new airframes or updates) to the fleet } \\
\text { of helicopters (currently } 25 \text { years old) }\end{array}$ & 9 & $26^{+}$ & 18 \\
\hline Helicopter sustainment system & $\begin{array}{l}\text { Sustains the operational capability of } 63 \text { helicopters used } \\
\text { for command and control }\end{array}$ & 0 & $26^{+}$ & 15 \\
\hline Peacekeeper sustainment system & $\begin{array}{l}\text { Maintains the capability of the Peacekeeper intercontinental } \\
\text { ballistic missile to deliver up to } 10 \text { independently targeted } \\
\text { warheads with great accuracy }\end{array}$ & 0 & 14 & 201 \\
\hline Space-based laser & $\begin{array}{l}\text { Will deliver through many satellites lethal thermal energy to } \\
\text { ground, airborne, and space targets }\end{array}$ & 16 & $26^{+}$ & 1,209 \\
\hline
\end{tabular}

Table 1: A sample of space systems shows their anticipated years of operation and their average annual cost. Space Command depends on sophisticated and costly systems, such as these, to achieve its goal of air and space superiority. Each candidate system may offer options with various development and operational schedules. 


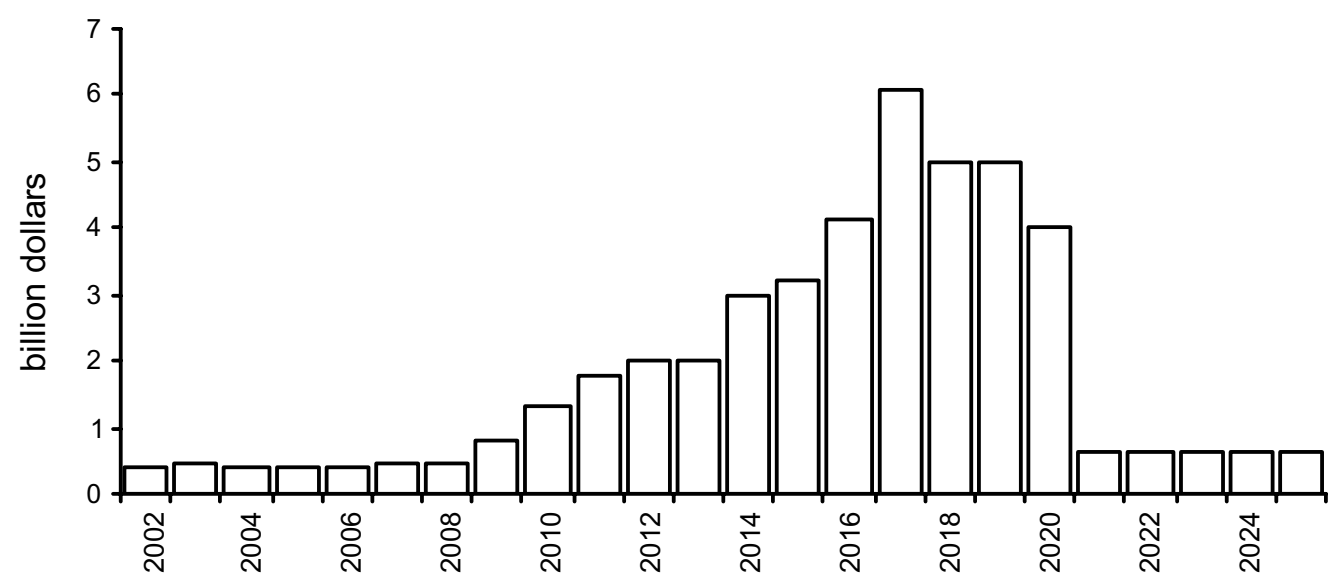

Figure 1: By adopting a candidate system, Space Command commits fixed expenditures over many years. It would bear most of the $\$ 44$ billion cost for this particular system from fiscal years 2014 through 2020 when most of its components would be launched into space. This system would achieve full operational capability (FOC) in 2020.

will be used to detect terrestrial and airborne objects, such as troops and satellites that may otherwise be obscured in the visible spectrum. This system has an average yearly cost of over $\$ 1$ billion. The space maneuver vehicle is a concept for a future system expected to help Space Command maintain operational satellites; it has a projected yearly cost of $\$ 425$ million. The conventional strike launch system is used to propel precision-guided bombs at high velocity to terrestrial targets. If the costs are spread over 24 years of operation, the launch system will cost an average of $\$ 50$ million yearly. The space-based laser will deliver lethal thermal energy via satellites to ground, airborne, and space targets and has an average yearly cost of over $\$ 1$ billion.

These systems require high up-front expenses (Figure 1) compared with those currently in operation or being shut down. They usually require years of research and development before they become operational. For example, a launch vehicle and the corresponding system to be launched require extensive preparation for deployment, including ground support and personnel training. Once a space system has been launched, the cost of maintaining it is a small part of its total (life-cycle) cost, consisting primarily of the costs of operating and maintaining ground stations and personnel.
We describe an integer linear program called the space command optimizer of utility toolkit (SCOUT) and its use within Space Command's space and missile optimization analysis (SAMOA) to assemble the 1997 and 1999 strategic master plans submitted to Congress. Early in SCOUT's development, the US Air Force asked us to refine the mathematical optimization model for SCOUT and find ways to expeditiously solve it. We met these requests between 1997 and 1999. SCOUT is a capital-budgeting model with some distinguishing features: It is large and includes a long time horizon, and it accounts for many dependent and synergistic system alternatives and several types of budget constraints.

\section{Overview of SAMOA}

SAMOA is a collection of analysis techniques Space Command uses to select from hundreds of candidate systems a set that best satisfies its requirements over a 24-year horizon. Each system option consists of a system type, such as a launch vehicle (Figure 2), satellite, or radar, and the start and stop dates of use. The number of launches required by type of vehicle and year is an important consideration. Space Command used SAMOA in 1997 and 1999 to develop Space Command's strategic master plan. 


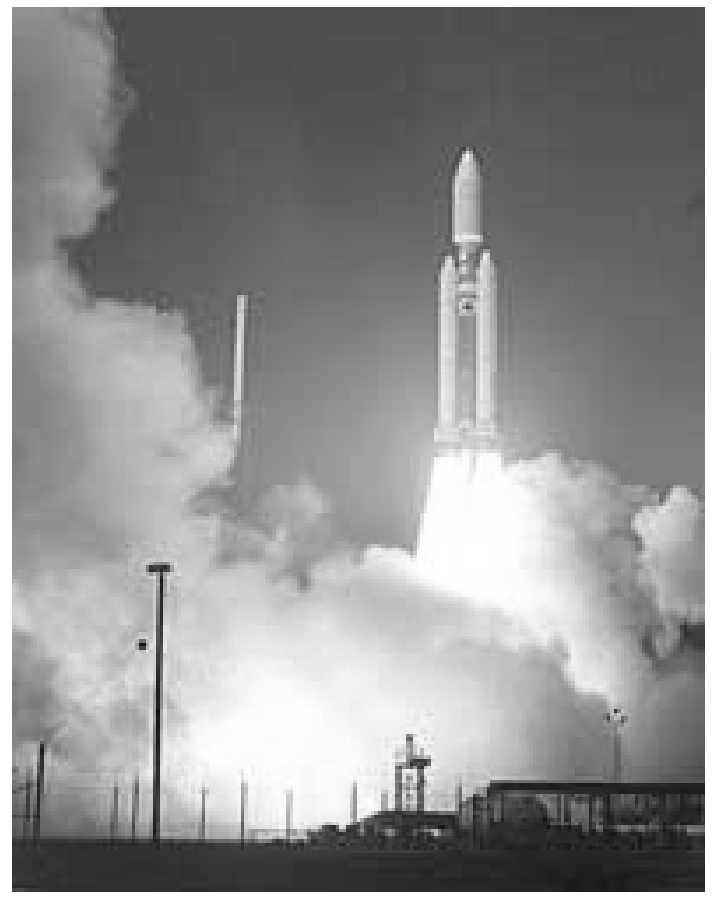

Figure 2: A Titan IVB missile launches a satellite from Cape Canaveral. This expendable launch vehicle can boost up to 47,800 pounds into lowEarth orbit or more than 12,700 pounds into geosynchronous orbit 22,300 miles above Earth. The payload joins a constellation of similar satellites that Space Command uses to provide early warning of missile launches worldwide (US Air Force 2001). The launcher and the satellite are components of separate space systems, but the satellite requires the launcher.

SAMOA consists of five steps: mission area assessment, mission needs analysis, mission solution analysis, portfolio selection, and refined-portfolio selection.

In the assessment step, mission area teams follow current administration guidance to divide mission areas into measurable operational tasks that Space Command needs to accomplish. Each planning area consists of a set of goals or target capabilities, and achieving each target capability requires that Space Command perform some set of tasks. For example, to achieve aerospace superiority, it must dominate the air and operations in, from, and through space. Air domination consists of two tasks: suppressing adversaries' air defenses and neutralizing adversaries' air and cruise missile capabilities. Table 2 shows the eight planning areas with their associated capabilities.

\begin{tabular}{|c|c|}
\hline Planning Areas & Associated Capabilities \\
\hline Aerospace superiority & To dominate air and space operations \\
\hline Rapid global mobility & $\begin{array}{l}\text { To deploy space assets to provide access to, } \\
\text { from, and through space }\end{array}$ \\
\hline $\begin{array}{l}\text { Global attack and } \\
\text { precision engagement }\end{array}$ & To attack surface targets \\
\hline Information superiority & $\begin{array}{l}\text { To conduct offensive and defensive } \\
\text { counter-information operations and to gain } \\
\text { and exploit information on events and threats }\end{array}$ \\
\hline $\begin{array}{l}\text { Global awareness and } \\
\text { command and control }\end{array}$ & $\begin{array}{l}\text { To monitor and assess conditions } \\
\text { and to plan and execute military operations }\end{array}$ \\
\hline Agile combat support & $\begin{array}{l}\text { To protect and sustain forces and to support } \\
\text { military and government installations }\end{array}$ \\
\hline Quality peopl & To recruit, train, promote, and retain personnel \\
\hline nnovation & To support new developments \\
\hline
\end{tabular}

Table 2: Mission-area assessment organizes Space Command's capabilities into eight planning areas. Each planning area consists of a set of capabilities, and each capability requires that some set of tasks be completed. For example, achieving aerospace superiority requires dominating operations in, from, and through space. Air domination consists of two tasks: suppressing adversary air defenses and neutralizing adversaries' air and cruise missile capabilities. Space domination consists of five tasks: protecting friendly (allies') space capabilities, protecting friendly missile capabilities, neutralizing adversaries' space capabilities, providing national and theater missile defense, and operating space assets.

In the needs analysis step, the teams identify the end objectives for each task and any existing shortfall Space Command has in achieving a particular task with a current system. The teams score current systems against tasks and assign measures of shortfall that indicate a system's complete, partial, or lack of coverage with respect to meeting a task.

In the mission solution analysis step, the teams weight tasks to indicate priority, determine the ability of candidate systems to fulfill tasks (Parnell et al. (1998) describe such an assessment), assess the costs of systems, and arrive at the projected budget for each year throughout the 24-year planning horizon. A candidate system's score is the weighted sum of its contribution for each measure toward the coverage (or value) it alone provides for each applicable task. This score is normalized and rounded to the nearest integer in the interval $[0,10]$. The contribution from several candidate systems that perform the same task can be the maximum contribution from 


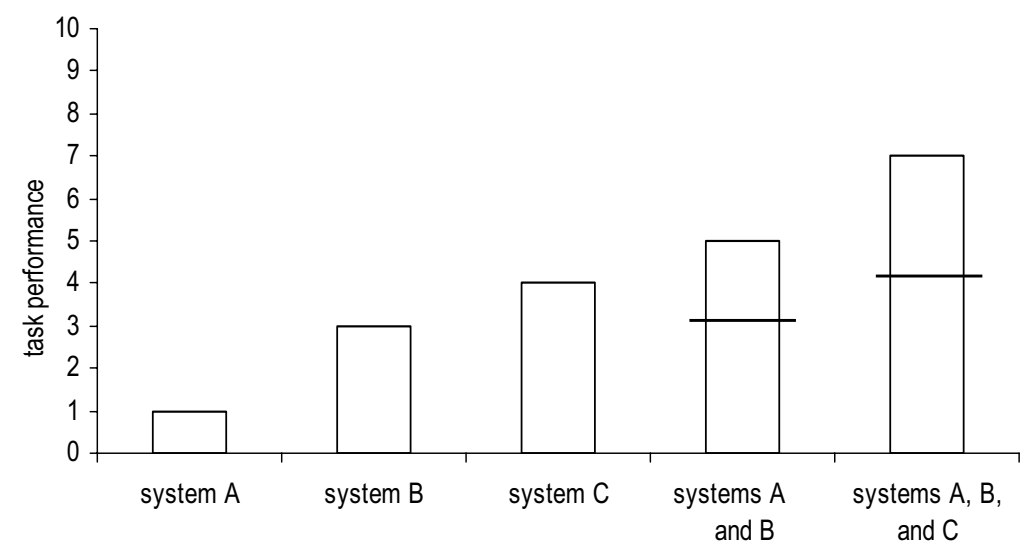

Figure 3: Space systems may perform better as synergistic-group systems. For a particular task, the synergisticgroup system A and B performs better than either of its components does independently. The synergistic-group system A, B, and C also offers synergistic performance. Other combinations may not. The horizontal bar dividing the performance of each synergistic-group system shows the contribution of the best component task; any combined performance in excess of the contribution of the best component task is synergistic. Accounting for synergy among systems is difficult when seeking to procure a maximal-performance portfolio of space assets.

any one of them, or perhaps more than this maximum if the systems act as a synergistic-group system (Figure 3), which we define as contributing more towards a particular task than what an individual system would contribute, but not necessarily more than the sum of the contributions from each system in the group. For example, when operating alone, the milstar satellite, which encompasses an information system that links ground, sea, undersea, and airborne systems, provides 80 percent of what is needed to perform the task of providing global-satellite communications; the extremely high frequency polar-interim system, an information system that provides satellite communications for the polar regions not reached by other satellites, independently provides 70 percent of what is needed to perform the same task; the global-broadcast system, another information system providing large-bandwidth one-way communications, achieves 80 percent of this task; and the defense satellite communication system, an information system that provides high-priority, secure communication between ground, sea, and air units of the US military and other government agencies, lends 80 percent towards performing this task. Together, and only together, these systems acting as a synergistic-group system provide 90 percent of what is needed to perform this task.

In the portfolio selection step, SCOUT selects a set of candidate systems that best meet Space Command's objectives while adhering to system operational constraints and budget limitations.

In the refined-portfolio selection step, Air Force officers rely on their expert judgment to evaluate and modify the set of systems that SCOUT has selected. The officers refine the recommendations based on political considerations and other factors not easily stated mathematically and thus not in SCOUT.

The mission area teams gather and prepare much of SCOUT's data in the first three steps of SAMOA: mission area assessment, mission needs analysis, and mission solution analysis. The teams categorize these data in the following seven groups: task coverage scores, system timing, launch timing, system and launch vehicle annual costs, per-launch costs, launch requirements, and budget restrictions.

Specifically, the teams assess each system's ability to perform each relevant task over three epochs: nearterm (first six years), mid-term (next eight years), and far-term (the remaining 10 years). 
Associated with each system is a list of possible start and stop years. In addition, the contractor building the system specifies the lead time for each system, that is, the number of years before it will become operational. By including lead times, the team enables the model to account for the cost of the system during the years it is not in operation.

Each system has a set of potential launch times.

The yearly system and launch-vehicle costs (except per-launch costs) run from the first year of research and development through the last possible year of operation.

The per-launch costs for each launch vehicle are a function of the operational dates of the systems that require launches and the number of times a launch vehicle provides launches over its lifetime. The total costs associated with the latter are accounted for by specifying for each launch vehicle (1) which launch vehicles are capable of launching and technologically available to launch a given system into orbit, (2) the annual number of launches required to build and maintain the system constellation, and (3) the perlaunch costs for a launch vehicle.

The carrying capacity of each type of launch vehicle dictates which payloads it can launch. The launch requirements also specify how many launches each system requires each year.

Based on congressional estimates, Air Force officers specify the budget for each year and each set of years throughout the planning horizon.

After the team assembles these data in the first three steps of SAMOA, SCOUT selects optimal portfolios, and the Air Force officers refine the resulting solutions. In the remainder of this paper, we focus on the two last steps in SAMOA.

\section{Selecting an Optimal Portfolio Using SCOUT}

Once the teams define task requirements and assess the ability of each candidate system and synergisticgroup system to meet these requirements, SCOUT unravels all the complex interactions among candidate system options, including when Space Command can adopt them and what years it must fund them, and selects an optimal portfolio of investments.

Brown et al. (2003) characterize SCOUT as a longterm capital-planning model, in contrast to civilian long-term capital-budgeting models (Clark et al. 1989, Weingartner 1963). Related military optimization models have been reported in the literature: Brown et al. (1991) planned the long-term modernization of the US Army's helicopter fleet using a model called PHOENIX, Loerch (1999) and Loerch et al. (1999) discuss the long history and use of PHOENIX progeny, while Donahue (1992), Ihde (1995), Carr (1996), and Field (1999) present optimization-based long-term capital-planning models using real data to solve a variety of real military problems. Newman et al. (2000) offer a comprehensive literature review.

SCOUT recommends a mix of system options and launches that minimizes shortfalls in task performance and takes into account constraints on budget and launch vehicle demand and availability. It selects at most one option for each system over the planning horizon, follows logic governing the precedence and interdependence among candidate systems, and adheres to bookkeeping relationships.

SCOUT selects candidate systems and launches according to rules governing their compatibility and interdependence. Launch capabilities must be sufficient to provide the launches required for a given candidate system, launch vehicle, and year. A launch vehicle must be operational before it can be used. A candidate system that depends on a primary system can operate only if that primary system is also in operation (Figure 4). For example, the securityforces-modernization system (which provides security for launch facilities) must be operational when the peacekeeper-sustainment system (which maintains the Peacekeeper missile) is operational. Also, a synergistic-group system depends on all of its component systems.

A prerequisite system must start operating before a candidate system that depends on it can start operating (Figure 4). For example, the nationalenvironment-monitoring satellite system can start operating only after the national-polar-orbiting system, because the former requires the ground stations of the latter for tracking its satellites. 

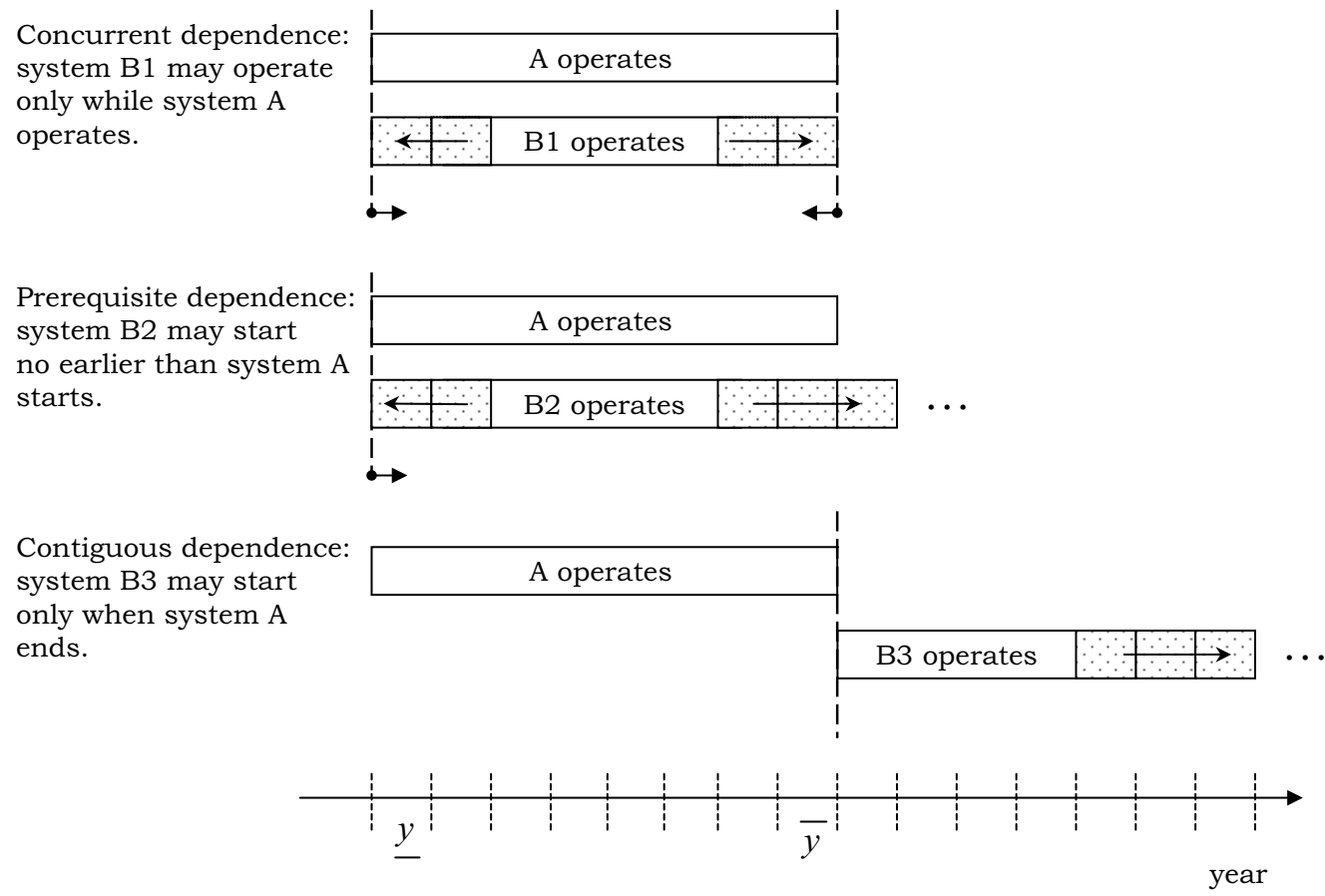

\begin{abstract}
Figure 4: When a new space system can begin operating (join an operational portfolio) depends on the timing of the other systems' operations. System A starts operating during year $y$ and stops after $\bar{y}$. The concurrent dependence of candidate system $B 1$ on $A$ restricts it to operating only when $\bar{A}$ does. The prerequisite dependence of $B 2$ on A prevents it from starting before A does. The contiguous dependence of B3 on A requires it to start operating right after $A$ ceases operation. In addition to these temporal dependencies, candidate systems are also governed by constraints on the portfolio, such as "select at most (or exactly) $n$ of these," and by budget.
\end{abstract}

A contiguous-dependent candidate system must start operating immediately after the related system that it replaces stops (Figure 4). For example, the evolved expendable launch vehicle must replace the atlas and delta launch vehicles as soon as they cease operation.

Space Command can procure, at most, one startdate, stop-date option of a candidate system over the planning horizon.

Space Command can procure, at most, one variation of a candidate system. Some systems that provide the same value differ in the technology they employ and their use may be mutually exclusive. For example, Space Command can choose either the helicopter-replacement system or the helicoptersustainment system but not both, because replacing the helicopter fleet is mutually exclusive with upgrading the existing fleet.

Space Command must procure one of the two or more candidate systems that perform some required task. For example, the five versions of space-based radar will differ in how they track ground targets, how they track air targets, how they reduce risk to operating personnel, and how much area they cover. Space Command must adopt one of these versions.

Constraints on the annual Space Command budget restrict the total planned costs, except launch costs, which are budgeted separately. While the fully operationally capable (FOC) year for a candidate system is the first year that it contributes to performing required tasks, the costs for a system may begin many years earlier and may even continue after it ceases 
operation. The bulk of the costs for many systems go for research, development, and initial deployment.

Some budget constraints restrict total costs for all systems over five-year epochs, admitting some flexibility for very expensive candidate systems such as launch vehicles that can be manufactured ahead of time and stored for future use.

The objective function for SCOUT expresses total discounted penalty dollars, with terms for penalties for annual shortfall in task performance and for violation of annual or epochal budget constraints. We can adjust a penalty discount rate to reduce the influence of far-term violations or not.

We give a simplified mathematical formulation of SCOUT in the Appendix.

\section{How Space Command Uses SCOUT}

SCOUT iteratively determines a set of efficient portfolios as follows. It seeks to discover a good solution, and when it discovers one (say, within five percent of integer optimality), it archives that portfolio. We add a constraint to preclude that portfolio from reappearing in the solution (Appendix), and we solve the problem with this restriction. Eventually, the optimal penalties grow as the quality of the restricted solutions degrades, until SCOUT reaches a cutoff point.

Among all the selected portfolios, specific candidate investments may appear many times, and we take these multiple selections as a signal that these are attractive, robust candidates. We can fix alternate candidate systems or specific system options in and out of seed portfolios and use SCOUT to examine the efficient fruits of these restrictions. Ultimately we rely on expert judgment to decide which portfolio is most attractive; this judgment is likely to incorporate considerations exogenous to the optimization model. For instance, an expert might judge that a portfolio includes too many systems that depend on a single technological development.

SCOUT reports the following for each portfolio: (1) each selected system, along with its funding start year, FOC year, and stop year; (2) the coverage each selected system provides for each relevant task during each year; (3) the maximum coverage the portfolio provides for a task in each year; (4) the launchers to be used for each satellite system, including the number of launches a selected launch system provides each year; (5) per-launch costs by year and launch vehicle; (6) system expenditures by year, excluding launch costs; and (7) total yearly expenditures (excluding launch costs) compared with the yearly budget.

Senior Space Command decision makers carefully review the selected mix of system options. They modify the portfolio based on their experience and judgment. For instance, SCOUT may suggest expenditures over the budget that they can mitigate or eliminate by modifying the funding profile of a selected system option. They may synchronize the start and stop dates of selected system options with those of related systems not considered in the model. Congressional legislation may require Space Command to choose a candidate system that SCOUT might not otherwise recommend.

Space Command uses SCOUT initially without forcing any selections. However, it is also useful for optimally untangling the consequences of exogenous must-buy restrictions. For instance, the political reality of an administration's stance on missile defense may force Space Command to select certain technologies (or systems that contain those technologies).

Because SCOUT considers a finite planning horizon, it suffers from end effects. SCOUT cannot see the benefit of procuring a system that requires funding during the planning horizon but provides little operational capability before the end of the horizon. In the long term, such systems may be beneficial or deemed necessary. For example, space-based radar should prove valuable for many tasks, but because it requires years of funding before it becomes operational, Space Command will begin to realize its benefits only at the end of the planning horizon. SCOUT and the strategic master plan both use a 24-year horizon. The US Air Force uses only the first 18 years of the strategic master plan in planning its procurements. This mitigates end effects.

SCOUT sometimes lacks sufficient fidelity to discriminate among small differences in task contributions. For example, it does not differentiate between sensing objects in low, medium, or high Earth orbits. Some systems cannot sense low orbits, and some cannot sense high orbits. SCOUT might suggest only 
a single system, but an expert knows that two are needed. Although the modelers could restate the task requirements in finer detail and could repeat a lot of analysis, sometimes it's just easier to let experts fix a problem.

Senior planners with experience and judgment are essential for assessing the quality of proposed portfolios. A senior SAMOA team chief for each mission area certifies that the proposed portfolio responds to that mission area's requirements.

\section{Decisions}

In 1999, Space Command considered about 200 candidate systems for adoption in the 2002-2025 planning horizon, each with associated options for start and stop dates. The number of options for start and stop dates varies dramatically by system. For example, a satellite with a predetermined start date and a fixed life span might have just one start-stop option, but a launch vehicle that can be selected at various years throughout the horizon and that has various possible operating lifetimes might have 50 start-stop options. The 200 candidate systems yielded about 5,000 feasible system options. Of the 200 systems, 27 were either already operational or had already been selected. Space Command was required to purchase an additional 19 systems because of congressional legislation or by direction of senior officers; however, even for these must-buy systems, the start and stop dates were not predetermined and constituted an additional 20 options per required system. A total of 74 systems appeared in the final strategic master plan portfolio produced with SCOUT's help.

Some of the important systems recommended for purchase in 1999 are (1) the space-based laser, which would help the US to dominate air and space operations by performing the following tasks: suppressing adversary air defenses, neutralizing adversary air and cruise missile capabilities, neutralizing adversaries' space capabilities, providing national and theater missile defense, and neutralizing or countering an attack from various types of targets; (2) minuteman sustainment, which helps the US to dominate space operations and attack surface targets to protect its allies' missile capabilities and neutralize various types of targets; (3) the evolved expendable launch vehicle, which will deploy other space systems and lifts systems, for example, global-positioning systems, that add significant military capabilities, for example, navigation, to our space operations; and (4) a version of the spacebased radar that obtains information on space, surface, and subsurface events, activities, and threats.

Several synergistic group systems chosen in 1999 include (1) the global broadcast system, the extremely high frequency polar-interim system, the defensesatellite-communication system, and the milstar satellite; (2) the extremely high frequency polar-interim system and the milstar satellite (a synergistic-group system distinct from the system listed in (1)); and (3) a conventional-strike system and the space-operations vehicle, a combination of a space shuttle and a fighter plane designed to conduct multiple military flights. The first two groups provide enhanced tracking and dissemination of information. The last group provides enhanced launch capability.

Figure 5 shows the pattern of total investments required by the system portfolio in the strategic master plan. Figure 6 shows the total coverage of tasks for the systems in the strategic master plan. A total of 10 points can be assigned to each task, and 34 tasks require coverage. Although task coverage falls short of the maximum 340 possible points, task coverage does, in general, increase over time, and by the end of the planning horizon, 29 of the 34 tasks gain some coverage.

SCOUT is an optimization model, and optimization models are notorious (and very useful) for finding erroneous data. In 1999, initial trials with SCOUT highlighted inconsistent cost units and some missing cost data, resulting in our underestimating true costs. SCOUT also identified relationships between candidate systems that were improperly defined because of confusion between, for example, precedence and synergistic interactions. We fixed these errors before we made the final model runs.

\section{Conclusions}

The strategic master plan for 1999 included planned investments totaling about $\$ 310$ billion. The congressional impetus (US Government Accounting Office 


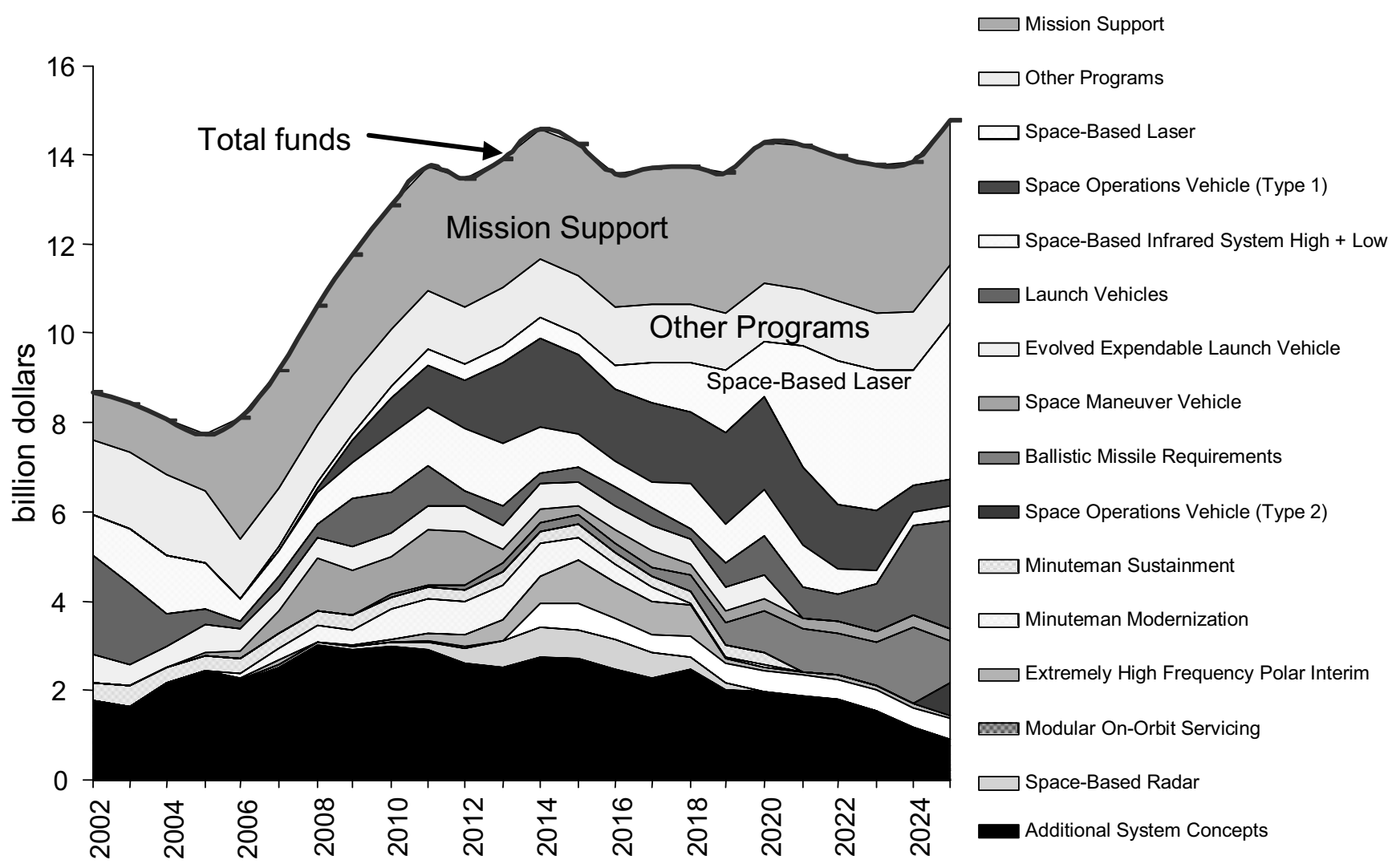

Figure 5: In the planned funding profile for the $\mathbf{1 9 9 9}$ strategic master plan, a few important systems are depicted separately (Space Command 2000, p. 116). The aggregate category mission support consists of such activities as training flight-control officers. Other programs include such systems as a space warfare center; these systems do not appear in the SCOUT optimization model but must fit into the total budget. Senior planners always need to modify cost profiles and start and stop dates to produce a final budget. SCOUT gives these experts a starting portfolio that is already reconciled in mathematical detail.

2000) calls for better-coordinated planning of space and nonspace systems. SAMOA and, in particular, SCOUT have provided Space Command with sound guidance for its procurement decisions.

This planning effort is the best-staffed and most scrupulously managed example of optimizationbased capital planning that we have ever seen. Since 1999, Space Command, along with several other commands, Air Force Special Operations Command and Air Mobility Command, have used SAMOA to help create their strategic master plans. Since then, SAMOA has also evolved and names have changed, but this 1999 snapshot exhibits most of the tran- scendent, distinguishing features of these important capital-planning problems.

\section{Appendix}

SCOUT features both conventional and elastic constraints (Brown et al. 1997) and a linear objective function principally consisting of elastic penalty terms. The elastic constraints admit solutions that would customarily violate feasibility and charge a penalty per unit violation. Elastic constraints are denoted by a dot over the relational operator (e.g., $\dot{\leq}, \dot{\geq}$ ). For ease of presentation, we have excluded the elastic variables from the formulation, and we define compound index 


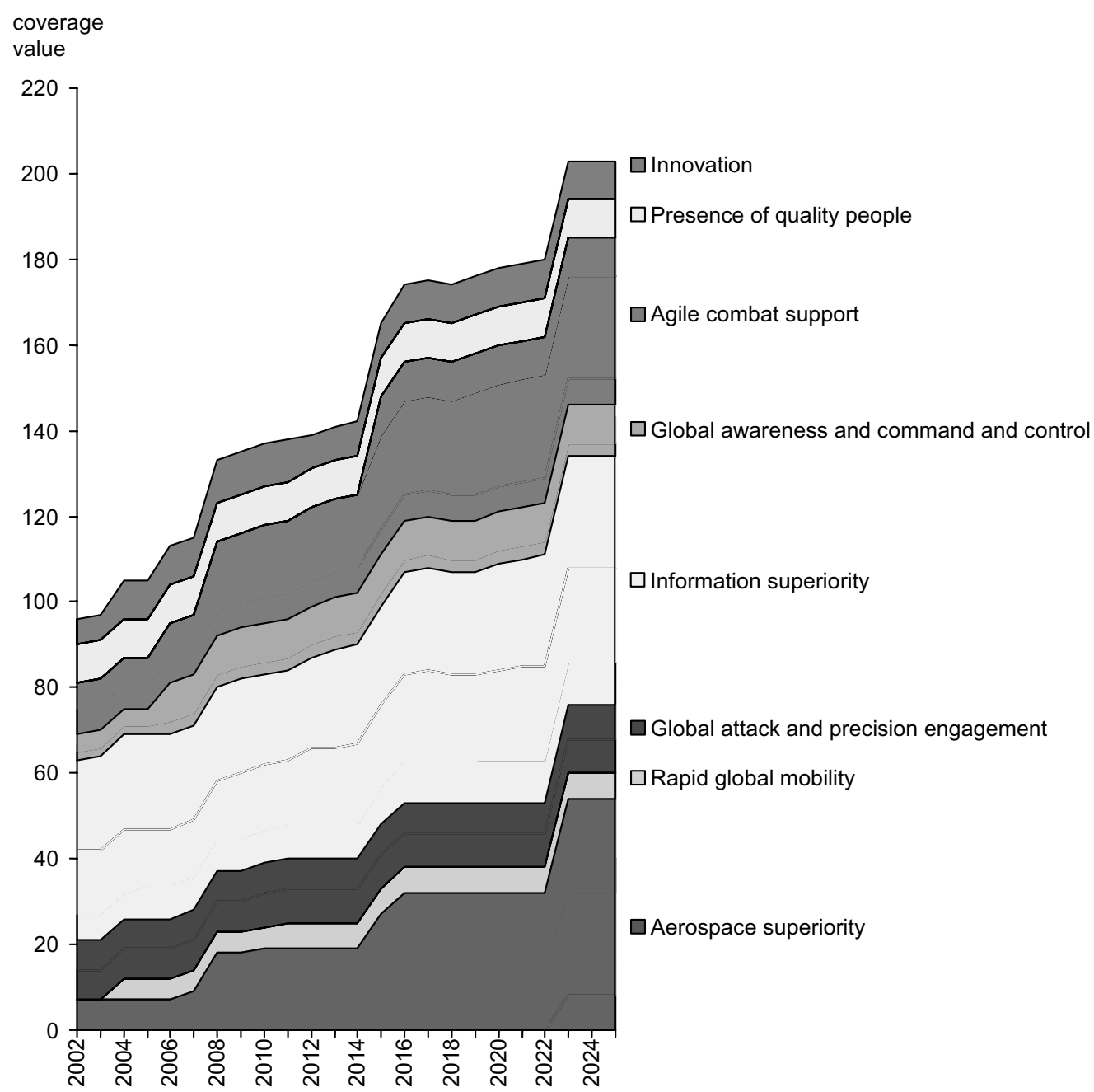

Figure 6: The system portfolio selected in 1999 provides coverage for planning area tasks that increases over time, but it does not cover all tasks within every planning area. The coverage for each task is indicated on a scale of 1 to 10, and 34 tasks require coverage (Space Command 2000, p. 144). Although task coverage falls short of the maximal 340 possible points, it generally increases over time. By the end of the planning horizon, 29 of the 34 tasks receive some coverage.

sets only for the instances that exist. We give units in brackets next to each definition. We give monetary data in constant (1998) million dollars (\$M). Newman et al. (2000) provide a more detailed formulation.

\section{Indices and Sets}

$s=$ candidate system (current system or concept for a future system).

$s=$ system that requires launching.
$\widehat{S}=$ system that provides launching.

$y=$ fiscal year (e.g., $y=1$ (2002), 2 (2003), .., 24 (2025)).

$\underline{y}, \bar{y}=$ start year, end year (first and last years of operation).

$(s, \underline{y}, \bar{y})=$ candidate system option.

$e=$ epoch (contiguous set of years).

$\Upsilon_{e}=$ set of contiguous years $y$ in epoch $e$.

$l=$ launch vehicle. 


$$
\begin{aligned}
& k=\text { task. } \\
& a=1, \ldots, A=\text { performance achievement increment }
\end{aligned}
$$
(e.g., 1-10).

\section{Data}

$\overline{\text { budget }}_{y}=$ budget allocated for year $y$ [\$M]. $\overline{\text { epochbudget }}_{e}=$ budget allocated for epoch $e$ [\$M]. $\operatorname{cost}_{s, y, \bar{y}, y}=$ cost to develop candidate system option $(s, \underline{y}, \bar{y})$ incurred in year $y[\$ \mathrm{M}]$.

launchcost $t_{\widehat{s}, y}=$ cost per launch with system $\widehat{s}$ in year $y$ [\$M per launch].

vehicles $_{\widehat{s}, y, \bar{y}, y, l}=$ maximum number of launches that system option $(\bar{s}, \underline{y}, \bar{y})$ can provide in year $y$ with vehicle $l$ [launch].

launchreqt $t_{s, y, \bar{y}, y, l}=$ launch requirements for system option $(s, \underline{y}, \bar{y})$ during $y$ with vehicle $l$ [launch].

$\operatorname{perform}_{s, k}=$ how well system $s$ performs task $k$ [value].

goal $_{k, a}=$ increment $a$ of performance goal for task $k$ (values increase with $a$ ) [value].

\section{Decision Variables}

$\operatorname{SELECT}_{s, y, \bar{y}}=1$ if system option $(s, \underline{y}, \bar{y})$ selected, $=0$ otherwise.

$\mathrm{LAUNCH}_{\widehat{s}, y, l}=$ number of launches by system type $\widehat{s}$ in year $y$ with vehicle $l$ [launch].

\section{Formulation}

s.t.

$$
\begin{aligned}
& \sum_{\underline{y}, \bar{y}} \operatorname{SELECT} T_{s, \underline{y}, \bar{y}} \leq 1 \quad \forall s, \\
& \sum_{\substack{(s, \underline{y}, \bar{y}) \mid \underline{y} \leq y \leq \bar{y} \\
\text { Aperform }_{s, k} \geq \text { goal }_{k, a}}}(A-a+1) \text { SELECT } T_{s, \underline{y}, \bar{y}} \\
& \dot{\geq}(A-a+1) \quad \forall k, a, y, \\
& \sum_{(s, \underline{y}, \bar{y})} \text { launchreqt }_{\underline{s, y}, \underline{y}, y, l} S E L E C T_{\underline{s,}, \underline{y}, \bar{y}} \\
& \leq \sum_{\widehat{S}} \operatorname{LAUNCH}_{\widehat{s}, y, l} \quad \forall y, l,
\end{aligned}
$$

$$
\begin{aligned}
& \operatorname{LAUNCH}_{\widehat{s}, y, l} \\
& \leq \sum_{\underline{y}, \underline{y} \mid \underline{y} \leq y \leq \bar{y}} \text { vehicles }_{\widehat{s}, \underline{y}, \bar{y}, y, l} \operatorname{SELECT}_{\widehat{s}, \underline{y}, \bar{y}} \quad \forall \widehat{s}, y, l, \\
& \quad \sum_{(s, \underline{y}, \bar{y})} \operatorname{cost}_{s, \underline{y}, \bar{y}, y} \operatorname{SELECT}_{s, \underline{y}, \bar{y} \dot{\leq} \overline{b u d g e t}} \quad \forall y,
\end{aligned}
$$

$$
\begin{aligned}
& \sum_{(s, \underline{y}, \bar{y}), y \in \Upsilon_{e}} \operatorname{cost}_{s, \underline{y}, \bar{y}, y} \operatorname{SELECT} T_{s, \underline{y}, \bar{y}} \\
& +\sum_{\widehat{s}, y \in \Upsilon_{e}, l} \text { launchcost }_{\widehat{s}, y} \text { LAUNCH }_{\widehat{s}, y, l} \\
& \dot{\leq} \overline{\text { epochbudget }}_{e} \quad \forall e, \\
& \operatorname{SELECT} T_{s, \underline{y}, \bar{y}} \leq \sum_{\underline{y^{\prime}}, \bar{y}^{\prime} \mid \underline{y}^{\prime} \leq \underline{y} \wedge \bar{y}^{\prime} \leq \bar{y}} \operatorname{SELECT} T_{s^{\prime}, \underline{y}^{\prime}, \bar{y}^{\prime}} \\
& \forall(s, \underline{y}, \bar{y}) \text { concurrent with } s^{\prime}, \\
& \operatorname{SELECT}_{s, \underline{y}, \bar{y}} \leq \sum_{\underline{y}^{\prime}, \bar{y}^{\prime} \mid \underline{y}^{\prime} \leq \underline{y}} \operatorname{SELECT} T_{s^{\prime}, \underline{y^{\prime}}, \bar{y}^{\prime}} \\
& \forall(s, \underline{y}, \bar{y}) \text { prerequisite of } s^{\prime}, \\
& =\sum_{\underline{y}^{\prime}} \operatorname{SELECT} T_{s^{\prime}, \underline{y}^{\prime}, \bar{y}^{\prime}} \quad \forall s \text { contiguous after } s^{\prime}, \bar{y}^{\prime}, \\
& \operatorname{SELECT}_{s, \underline{y}, \bar{y}} \in\{0,1\} \quad \forall(s, \underline{y}, \bar{y}), \\
& \operatorname{LAUNCH}_{\widehat{s}, y, l} \geq 0 \quad \forall \widehat{s}, y, l, \\
& \underset{S E L E C T, L A U N C H E S}{\operatorname{minimize}} \text { penalties. }
\end{aligned}
$$

Constraints (1) insure that at most one system option is selected over the planning horizon. Constraints (2) determine task shortfalls by penalizing any task, performance category, or year for which no option offering sufficient performance is selected. Constraints (3) accumulate the number of launches, by type of launch vehicle and year, that are required by the selected system options that require launches. These launches may be required in years other than those selected. Constraints (4) require selection of launch system options sufficient to provide the required launches by type of vehicle and by year.

Costs are incurred before a system starts operating and may continue after it stops operating. Constraints (5) are annual elastic budget limits for expenditures on selected options but exclude launch costs. Constraints (6) elastically enforce epochal budget constraints on selected options, including launch costs.

Each constraint (7) requires that system $s^{\prime}$ must be operational if concurrent-dependent system $s$ is operational. Each constraint (8) ensures that system $s$ can start no sooner than prerequisite system $s^{\prime}$ does. Each constraint (9) stipulates that some 
contiguous-dependent candidate system $s$ must start operating right after system $s^{\prime}$ stops operation. Constraints (10) state binary and nonnegativity requirements. Not shown are packing (or partition) constraints that ensure that at most $n$ (or exactly $n$ ) of a set of candidate-system options are selected over the planning horizon. A packing constraint like this can be used to rule out a portfolio: For example, to preclude the complete set of systems in portfolio $p$, consisting of $|P|$ systems and the set of system options $\Omega_{p}$, from simultaneous selection while still allowing any proper subset of the systems, constrain

$$
\sum_{(s, \underline{y}, \bar{y}) \in \Omega_{p}} \operatorname{SELECT}_{(s, \underline{y}, \bar{y})} \leq|P|-1 .
$$

The objective function expresses total constant-year penalty dollars, with terms for penalties for violations of annual shortfall in task performance and for annual and epochal budget constraints (constraints (2), (5), and (6), respectively).

For purposes of exposition, we have simplified SCOUT here. For instance, we do not show the details about the lag between initial funding and FOC years, but it is an essential and complicating feature in SCOUT. The objective function has an additional tiebreaking term to encourage SCOUT to select a system only when this provides a gain in task performance. We also omit examples of trivial ad hoc side constraints (for example, to force selection of a system).

SCOUT typically exhibits about 10,000 constraints and 5,000 variables, with half of these variables binary. Solving SCOUT using commercially-available optimization software to within five percent of optimality usually requires less than an hour on a 500megahertz personal computer (Newman et al. 2000).

We can reduce SCOUT's solution time by discounting shortfall penalties so that far-term violations have less influence. We also improve performance by allowing research and development of concepts for future systems to be funded without requiring that a particular all-or-nothing binary option be selected. This relaxation permits full funding to be committed to an attractive future system but allows funding to be spread fractionally among all its options. These and other modifications preserve the essential essence of
SCOUT planning and make SCOUT much easier to use (Newman et al. 2000).

\section{Acknowledgments}

Many people contributed to SCOUT, and we are merely a subset that has, in addition, documented this application. We acknowledge the contributions made by US Air Force officers: Colonel Tom Clark, Captain Angela Giddings, Lt. Col. Lee Lehmkuhl, Lt. Col. Lynnette Whitsel, and Lt. Col. Kirk Yost. Joe Melton, Analysis and Engineering Division, Space Warfare Center, Schriever AFB, $\mathrm{CO}$, contributed so much to the budget-planning cycle reported here that we invited him as a coauthor, but he declined, yet graciously offered improvements in our exposition. We also acknowledge Bruce Merrill, Mike Tedeschi, and Tom DeLaCruz; and Naval Postgraduate School professors Rick Rosenthal and Kevin Wood.

\section{References}

Brown, G. G., R. F. Dell, A. M. Newman. 2003. Optimizing military capital planning. In submission.

_ _ _ R. K. Wood. 1997. Optimization and persistence. Interfaces 27(5) 15-37.

— , R. D. Clemence, W. R. Teufert, R. K. Wood. 1991. An optimization model for modernizing the army's helicopter fleet. Interfaces 12(4) 39-52.

Carr, D. A. 1996. Optimally scheduling theater missile defense procurement. MS thesis in operations research, Naval Postgraduate School, Monterey, CA.

Clark, J. J., T. J. Hindelang, R. E. Pritchard. 1989. Capital-Budgeting: Planning and Control of Capital Expenditures. Prentice-Hall, Englewood Cliffs, NJ.

Donahue, S. F. 1992. An optimization model for army planning and programming. MS thesis in operations research, Naval Postgraduate School, Monterey, CA.

Field, R. J. 1999. Planning capital investments in navy forces. MS thesis in operations research, Naval Postgraduate School, Monterey, CA.

Ihde, A. G. 1995. An optimization model for anti-armor weapon systems acquisition. MS thesis in operations research, Naval Postgraduate School, Monterey, CA.

Loerch, A. G. 1999. Incorporating learning curve costs in acquisition strategy optimization. Naval Res. Logist. 46(3) 255-271.

_, R. R. Koury, D. T. Maxwell. 1999. Value added analysis for army equipment modernization. Naval Res. Logist. 46(3) 233-253.

Newman, A. M., G. G. Brown, R. F. Dell, A. Giddings, R. E. Rosenthal. 2000. An integer-linear program to plan procurement and deployment of space and missile assets. NPS Technical report no. NPS-OR-00-005, Naval Postgraduate School, Monterey, CA.

Parnell, G. S., H. W. Conley, J. A. Jackson, L. J. Lehmkuhl, J. M. Andrew. 1998. Foundations 2025: A value model for evaluating future air and space forces. Management Sci. 44(10) 1336-1350. 
BROWN, DELL, HOLTZ, AND NEWMAN

US Air Force Space Command

Space Command. 2000. 1998-1999 Integrated Planning Process: Mission Solution Analysis and Integrated Investment Analysis, March 28.

United States Air Force. 2000. Mission Statements, www.af.mil/ news/factsheets, retrieved August 15.

2001. Air Force Titan IVB launch from Cape Canaveral, May 8, 2000, www.af.mil, retrieved January 9.
United States Government Accounting Office. 2000. Defense acquisitions: Improvements needed in military space systems' planning and education. GAO/NSIAD-00-81, Report to the Senate Armed Services Committee, May.

Weingartner, H. M. 1963. Mathematical Programming and the Analysis of Capital-Budgeting Problems. Prentice-Hall, Englewood Cliffs, NJ. 